\title{
Pre-glottal vowels in Shanghai Chinese
}

Yiya Chen

Department of Linguistics, Radboud University Nijmegen, the Netherlands

https://doi.org/10.36505/ExLing-2006/01/0017/000017

\begin{abstract}
This study examines the acoustic realization of two complementary sets of vowels in Shanghai Chinese: One appearing in open syllables only (OSVs) and the other in closed syllables with a glottal coda (PGVs). Two factors - consonant onset and prominence level - were controlled to test the null hypothesis that PGVs are reduced realization of the OSVs due to their short duration. Results showed spectral reduc-tion of the PGVs but suggested that PGVs cannot be the reduced realization of OSVs as both onsetless and prominent PGVs failed to be consistently realized with a more expanded acoustic vowel space, which was predicted by the reduction account. We propose that the spectral reduction of the PGVs is an inherent feature of the vowel's phonetic implementation.
\end{abstract}

\section{Introduction}

Shanghai Chinese is a $\mathrm{Wu}$ dialect spoken in the city of Shanghai. One interesting feature of the language is that it has two types of vowels: One occurs in CV syllables (i.e. open-syllable vowels, hereafter OSV) and the other in closed syllables with a glottal coda (i.e. pre-glottal vowels, hereafter PGV). It is clear that PGVs are much shorter than OSVs (Zee \& Maddieson 1979). The phonemic status of the PGVs, however, has been of much controversy (Chen \& Gussenhoven, submitted, and references therein). This paper seeks acoustic evidence to test the null hypothesis that PGVs are the reduced and more centralized realization of some of the OSVs, given the effect of short duration on vowel production (Lindblom 1963).

Two factors, consonant onset and prosodic prominence, which have been commonly recognized as important determinants of vowel reduction, were therefore carefully controlled. Studies on the effect of consonant environment on vowel formant patterns show that vowels in CVC are in general more centralized than that in the $/ \mathrm{hVd} /$ context, the classical "null" environment (Peterson \& Barney 1952), which is comparable to vowels in isolation (Stevens \& House 1963, Hillenbrand \& Clark 2001, among others). As for the effect of prosodic prominence, it has been shown that vowels occurring in a prosodically prominent position are longer and implemented with more effort, and consequently the underlying vowel target is better approximated (Fourakis 1991, van Bergem 1995, Moon \& Lindblom 1994, among others). If indeed PGVs are the reduced and more centralized realization of some of

ExLing 2006: Proceedings of 1st Tutorial and Research Workshop on Experimental Linguistics, 28-30 August 2006, Athens, Greece 
the OSVs, we then predict that PGVs with an onset and without focus should be the most centralized ones while onsetless OSVs with focus should show the most expanded vowel acoustic space.

\section{Methods}

The stimulus material comprises two sets of words: one set include five OSVs (i.e. i, u, $\varepsilon, o$, a) and the other three PGVs (i.e. I, $U, \Lambda$ ). Each set consisted of two subsets. One includes onsetless vowels and the other the same vowels with the onset $/ \mathrm{d} /$. Both sets are associated with a rising tone, the OSVs with Tone 3 and the PGVs with Tone 5 (indicated with superscripts), in terms of the traditional Chinese tonology (Xu and Tang, 1988).

The carrier sentence for the test stimulus $(X)$ is shown in (1). Bracket indicates boundaries of the tonal domain (where only the first tone of the domain is marked) Two types of questions were asked. One is about which word is on certain row and the other about which row a specific word is on. The same stimulus sentence would be uttered accordingly, with two prosodic patterns, one with the target word focused and the other without focus.

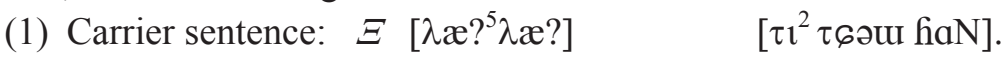
$X$ locative marker (L-M) $9^{\text {th }}$ row.
' $X$ (target morphemes) is on the $9^{\text {th }}$ row.'

Thirteen native speakers of Shanghai Chinese, ten female and three male, participated in this experiment. They were born between 1935 and 1950 and have lived most of their lives in Shanghai, mainly in the Xuhui District.

The stimuli were presented in Internet Explorer via a JAVA program, with randomized order of the stimuli. Two repetitions of the same stimulus in the same focus context were elicited. The recordings were made in stereo at the Shanghai Normal University, on a PMD660 Marantz recorder, with an AKG C477 microphone, at a $44100 \mathrm{~Hz}$ sampling rate, and later downsampled to $22050 \mathrm{~Hz}$ in GoldWave.

In Praat, the first and second formant frequencies of the vowels at the one-third and two-thirds temporal points (over the vowel duration) were computed using the LPC (autocorrelation) algorithms with its default settings for females $(5500 \mathrm{~Hz}$ for 5 formants) and males $(5000 \mathrm{~Hz}$ for 5 formants) respectively. The LPC spectra were occasionally recomputed with a larger number of formants ( 6 or 7 ) to separate merged formants.

For statistical analyses, the formant frequencies in Hertz were converted to the Bark scale using the formula by Traunmüller (1990) (Forman-Bark $=$ $[(26.81 /(1+1960 /$ Formant-Hertz $)]-0.53)$. Euclidean distance of each vowel to the center of a subject's F1-F2 vowel space was calculated. 


\section{Results and Conclusion}

To test the hypothesis that the PGVs are the reduced and centralized realization of the OSVs, Euclidean distance of each vowel was subjected to a linear mixed-effect model with Subject and Vowel as crossed random effects. The independent fixed-effect predictors included 1) position of the measurements (i.e. one-third vs. two-thirds), 2) vowel type (i.e. PGV vs. OSV), 3) onset (i.e. onsetless vs. onset 'd'), and 4) focus condition (i.e. focus vs. without focus). We observed significant three-way interactions for Focus*Type* Position $[\mathrm{F}(1,1650)=4.93, \mathrm{p}=0.026]$, Onset*Type*Position $[\mathrm{F}(1,1650)=$ $47.23, \mathrm{p}<0.0001]$, as well as for Onset*Focus*Position $[\mathrm{F}(1,1650)=5.45$, $\mathrm{p}=0.020]$.

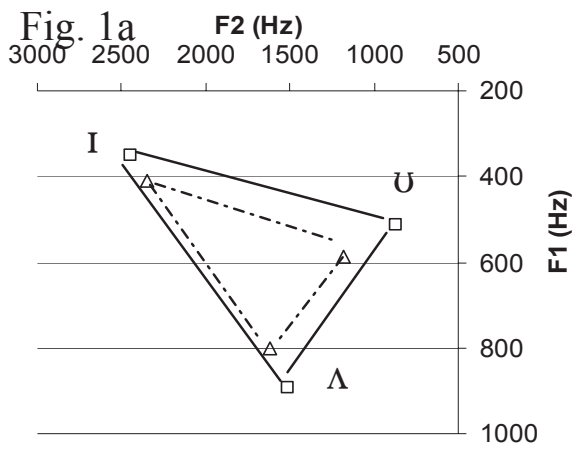

$\square$ onsetless

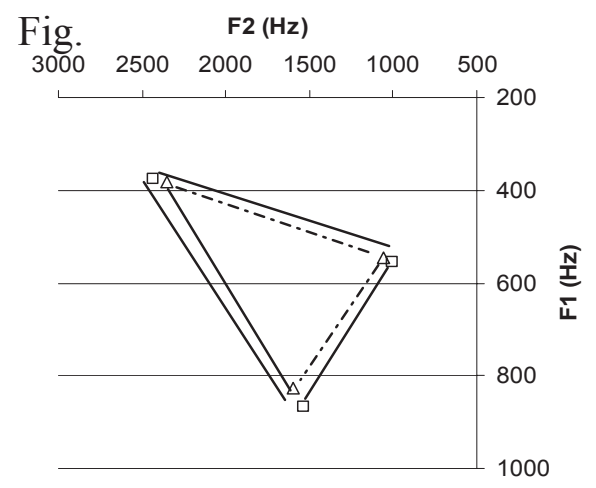

$\square$ focused

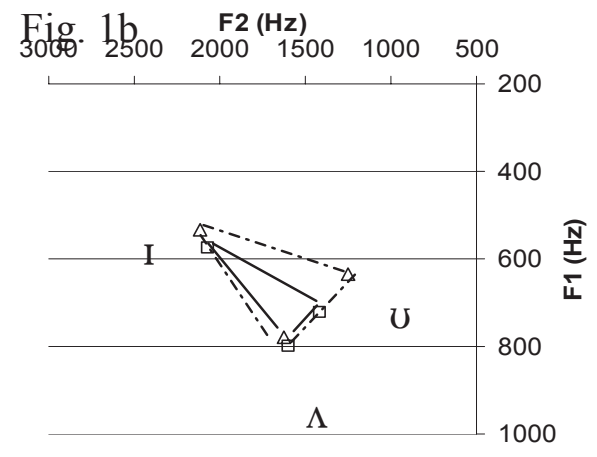

$\Delta$ onset d

Fig.

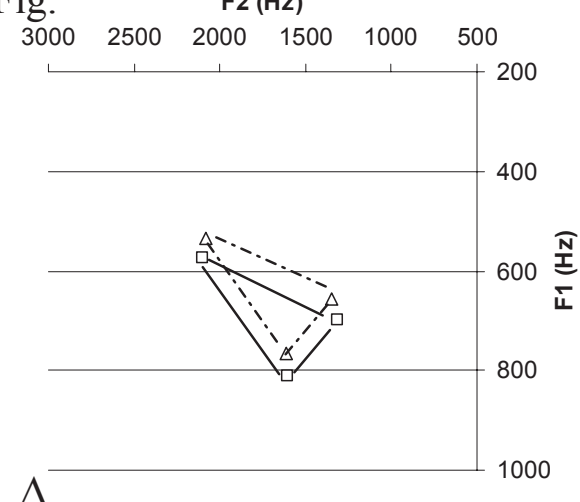

Figure $1 \&$ 2. Effect of onset and focus on PGV formants at one-third (a) and two-thirds (b) time points.

As shown in Figures 1-2, the interactions mainly reflect the different effects of onset and focus on the PGVs at the two-thirds time point (b) from that on the PGVs at the one-third time point (a) which was similar to that on 
the OSVs. Specifically, OSVs, measured at both time points, and PGVs, measured at the one-third time point, both showed more expanded acoustic vowel space in onsetless and focused conditions. PGVs measured at the twothirds time point, however, showed that their vowel space was more expanded when following the onset /d/ and lowered when under focus, whose different magnitudes resulted in the significant interaction of focus and onset. We therefore conclude that PGVs in Shanghai Chinese should not be the reduced and centralized realization of the OSVs. Rather, their spectral reduction may be seen as an inherent feature of the vowel's phonetic implementation.

\section{Acknowledgements}

I thank Carlos Gussenhoven whose insightful comments pointed me to the right direction, Joop Kerkhof who provided much help with data extraction, Harald Baayen for his generosity with both his expertise and time on the regression model, Wuyun Pan and Qin Gu for assistance with data collection, and my subjects, of course. Usual disclaimers apply. Support by a VENI grant from the NWO is also gratefully acknowledged.

\section{References}

Chen, Y. and Gussenhoven, C. Shanghai Chinese. Submitted.

Fourakis, M. 1991. Tempo, stress, and vowel reduction in American English. JASA 90: 1816-27.

Hillenbrand, J., and Clark, M. 2001. Effects of consonant environment on vowel formant patterns. JASA 109: $748-763$.

Lindblom, B. 1963. Spectrographic study of vowel reduction. JASA 35: 1773-1781.

Moon, S. and Lindblom, B. 1994. Interaction between duration, context, and speaking style in English stressed vowels. JASA 1992: 40-55.

Peterson, G. E., \& Barney, H.L. 1952. Control methods used in a study of the vowels. JASA 24: 175-184.

Stevens, K., \& House, S. 1963. Perturbation of vowel articulations by consonantal context: An acoustical study. Journal of Speech Hearing Research 6: 111-127.

Traunmüller 1990. Analytical expressions for the tonotopic sensory scale. JASA 1990: 98-100.

van Bergem, D. 1995. Acoustic and lexical vowel reduction. Studies in Language and Language Use 16. IFOTT: Amsterdam.

Xu, B. and Tang, Z. (eds.) 1988. A description of the dialect of the Shanghai City. Shanghai: Shanghai Education Press.

Zee, E. and Maddieson, I. 1979. Tones and tonal sandhi in Shanghai: Phonetic evidence and phonological analysis. UCLA Working Papers in Phonetics 45: 93129. 